\title{
Unikondiler Diz Artroplastisi İle Kombine Ön Çapraz Bağ Rekonstrüksiyonu Ameliyat Sonrası Dönemde Kanamayı Arttırır mı?
}

\author{
Does Unicondylar Knee Arthroplasty Combined With Anterior Cruciate \\ Ligament Reconstruction Increase Post-Operative Bleeding?
}
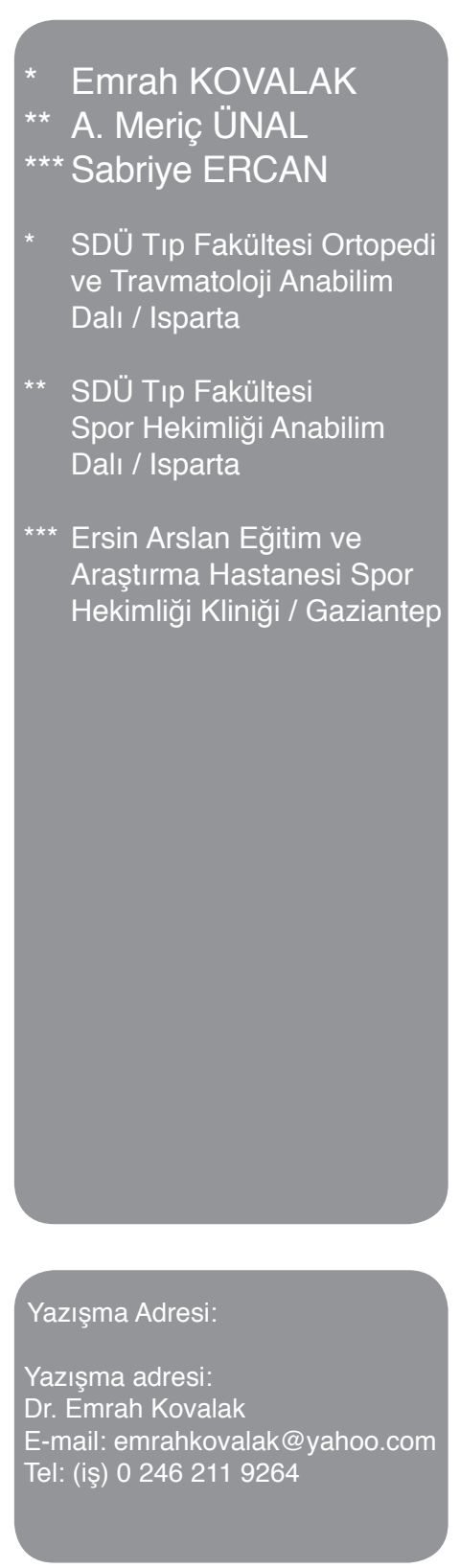

\section{Öz}

Amaç: Unikondiler diz artroplastisi (UDA) ile beraber ön çapraz bağ rekonstrüksiyonu yapılan hastalarda kanama miktarı ve kullanılan greft tipinin kanama miktarı üzerine olan etkisinin belirlenmesi. Hastalar ve yöntem: Primer medial kompartman osteoartriti tanısı ile unikondiler diz artroplastisi (UDA) yapılan hastalar- Grup A ve UDA ile beraber ön çapraz bağ (ÖÇB) rekonstrüksiyonu yapılan hastalar- Grup B olmak üzere iki gruba ayrıldılar. Grup B' yi oluşturan hastalar kendi içerisinde allogreft ve otolog hamstring tendon grefti (HTG) kullanılan hastalar olmak üzere iki gruba ayrıldılar. Her iki grupta 24 saatte drenden gelen kanama miktarı kayıt altına alındı. Bulgular: Grup A 28, Grup B ise 18 hastadan oluşmakta idi. Gruplar; yaş, cinsiyet, kilo ve boy açısından karşılaştırılabilir idi. Her iki grup arasında hemovak drenden ölçülen kanama miktarları arasında istatiksel bir fark saptanmadı $(p=0.86)$. Grup B'de hemovak drenden ölçülen kanama miktarı otolog HTG kullanılan grupta allogreft kullanılan hastalara göre daha fazla idi ( $p=0.043)$. Grup A ile otolog HTG ve allogreft kullanılan hastaların drenden ölçülen kanama miktarları karşılaştırıldığında istatiksel olarak bir fark saptanmadı $(p=0.058$ ve $p=0.65)$. Sonuç: ÖÇB ile kombine yapılan UDA de, ön çapraz bağ rekonstrüksiyonun oluşturduğu kanama miktarı özellikle allogreft kullanıldığında ihmal edilebilir düzeyde olup, kanama miktarı üzerine olumsuz etkisi yoktur.

Anahtar Kelimeler: Replasman artroplastisi, diz; Kanama, operasyon sonrası; anterior cruciate ligaman

\section{Abstract}

Object: To evaluate the post-operative bleeding in patients who had unicondylar knee arthroplasty (UKA) combined with anterior cruciate ligament (ACL) reconstruction and the effect of graft type on bleeding. Material and methods: The patients who had UKA comprised in Group $A$ and the patients who had UKA combined ACL reconstruction comprised in Group B. The patients, who participated in Group B, are also evaluated in 2 groups according to the used grafts such as allograft and autolog hamstring tendon graft (HTG). The drainage was recorded for 24 hours in both groups. Results: Group A was comprised of 28 and group B was comprised of 18 patients. Groups were comparable according to the age, sex, weight and height. There was no statistical significance between the groups according to the measured 
bleeding via hemovac $(p=0.86)$. In Group $B$, the measured bleeding was more in autolog HTG used patients than the patients who had allograft used with a statistical significance $(p=0.043)$. There was no statistical significance in measured bleeding when Group A compared with autolog HTG and allograft used patients $(p=0.058$ and $p=0.65)$. Conclusion: The bleeding is negligible and no additive effect on bleeding when UKA is combined with ACL reconstruction, especially when allograft is used.

Keywords: Replacement Arthroplasty, Knee; Hemorrhage, postoperative; Anterior cruciate ligament

\section{Giriş}

Yaşlı nüfusun artışı ile beraber gonartroz ve beraberinde diz artroplastisi uygulanma sıklığı da artmaktadır $(1,2,3)$. Diz artroplastisi seçenekleri arasında unikondiler diz artroplastisi (UDA) bikompartmental ve total diz artroplastisi (TDA) bulunmaktadır (3). Kontralateral ve patellofemoral kompartmanların sağlam olduğu medikal tedaviye yanıt alınamayan izole tek kompartman osteoartritlerinde tercih genellikle UDA'dir $(2,4,5)$.

Ön çapraz bağ (ÖÇB) yaralanması ise en sık karşılaşılan diz yaralanmalarından biri olup, bu dizlerde tibianın femura göre anterior translasyonu nedeni ile tibia-femoral eklemin posteromedial kısmında ikincil osteoartrit gelişimi sıktır $(6,7)$. ÖÇB yaralanması sonrası osteoartrit gelişen hastalar genellikle genç ve aktif hastalar olup UDA için en uygun yaş grubu olan genç ve aktif hastalardır $(7,8)$. Ancak, ÖÇB yetmezliği nedeni ile stabil olmayan dizlerde tek başına yapılan UDA sonrasında başarısızlık oranı yüksektir $(9,10)$. Bundan dolayı UDA ile kombine olarak eş zamanlı ön çapraz bağ ameliyatları önerilmektedir $(5,7,11)$. Bu hastalarda yüksek tibial osteotomi ile kombine ÖÇB rekonstrüksiyonu da bir seçenek olmasına rağmen sonuçları genel olarak UDA - ÖÇB rekonstrüksiyonundan daha başarısız olduğundan tercih edilmemektedir (11).

Ön çapraz bağ ve artroplasti ameliyatları sonrası oluşan hemartrozu önlemek için dren kullanımı açısından net kabul görmüş bir yaklaşım yoktur $(3,12)$.
Dren kullanılmasını önerenler; eklem içi efüzyonu azaltması, hematom oluşumunu engellemesi nedeni ile iyileşme sürecini kısalttığını, protez enfeksiyonu riskini azalttığını ve rehabilitasyonda daha verimli olunduğunu savunurken, aksini savunanlar ise cerrahi sonuçları arasında fark olmadığını, enfeksiyon riskini ve/ veya transfüzyon ihtiyacını arttırdığını belirtmektedirler (13-15).

Yazılı literatürde, TDA (15-19) sonrası dren kullanımı ile ilgili birçok çalışma bulunmakla beraber UDA sonrası dren kullanımı ve ameliyat sonrası kanama miktarları ile ilgili çalışma sayısı oldukça kısıtlı olup genellikle TDA ile karşılaştırma şeklinde dizayn edilmişlerdir $(3,4,15)$. Ayrıca, UDA ile kombine olarak yapılan ÖÇB ameliyatlarının sonuçlarını bildiren çalışmalarda ameliyat sonrası kanama miktarı ile ilgili bir veri yazılı literatürde bulunmamaktadır.

Bu çalışmada, UDA ve UDA ile kombine ÖÇB rekonstrüksiyonu yapılan hastalarda kanama miktarı ile kullanılan greft tipinin kanama miktarı üzerine olan etkisini belirlemeyi amaçladık.

\section{Hastalar ve yöntem}

Yerel etik kurulunun onayını takiben (21.12.2016/ no:176) çalışma amacı ile primer medial kompartman osteoartriti tanısı ile UDA yapılan hastalar- Grup A ve UDA ile beraber ön çapraz bağ (ÖÇB) rekonstrüksiyonu yapılan hastalar- Grup B olmak üzere iki gruba ayrıldılar. Grup B' yi oluşturan hastalar ise kendi içerisinde allogreft ve otolog hamstring tendon grefti (HTG) kullanılan hastalar olmak üzere iki gruba ayrıldılar.

Bilateral diz ameliyatı yapılan hastalar, daha önce majör kanama sorunu yaşayanlar, daha önce diz cerrahisi- yüksek tibial osteotomi ve ÖÇB rekonstrüksiyonu geçirmiş olan hastalar çalışma dışı bırakıldılar.

Ameliyat öncesi hastalara premedikasyon yapılmadı. Ameliyattan 1 saat önce profilaksi amacıyla 1gr sefazolin sodyum (Cefozin ${ }^{\circledR}$ 1gr IM/IV enjektabl flakon, Bilim İlaç San., İstanbul) 1 gr. $1 \times 1$ intravenöz olarak uygulandı ve $3 \times 1,24$ saat devam edildi. Ameliyattan 
12 saat önce tüm hastalara venöz tromboemboli profilaksisi amacı ile $40 \mathrm{mg}$ enoksaparin sodyum (Clexane ${ }^{\circledR} 4000$ Anti-xa lu/0,4 Ml, Sanofi Aventis İlaçları Ltd. Şti. İstanbul) $1 \times 1$ subkutan başlandı ve 3 hafta devam edildi.

\section{Cerrahi teknik}

Tüm hastalar supin pozisyonda, spinal anestezi altında, uyluğa pnömatik turnike tatbikini takiben (300 $\mathrm{mm} \mathrm{Hg}$ ) ameliyat edildiler.

\section{1a. Unikondiler diz artroplastisi:}

Grup A'da yer alan hastalarda UDA medial parapatellar, patella üst kutbundan tuberositas tibiaya uzanan 8-10 cm. longitudinal cilt insizyonu ile yapıldı. Medial kapsülotomi yapılarak ekleme ulaşıldı. Kuadriseps tendonu sağlam olarak bırakıldı. Patella laterale çekilerek medial tibio-femoral kompartmana rahat erişim sağlandı. Osteofitler temizlendikten sonra tekniğine uygun olarak sabit platformlu (Zimmer® Unicompartmental Knee Replacement, USA) çimentolu unikondiler diz protezi yerleştirildi. Ameliyat sonunda 1 adet $500 \mathrm{~mL}$ hacimli hemovak dren yerleştirilerek kanama kontrolü yapılmadan katlar anatomisine uygun olarak kapatıldı. Yara yeri pansumanı yapılarak elastik bandaj sarıldı ve turnike açıldı.

\section{1b. Unikondiler diz artroplastisi ve ön çapraz bağ rekonstrüksiyonu:}

Grup B' de yer alan hastalara ilk önce standart anterolateral ve anteromedial portaller kullanılarak tanısal artroskopi yapıldı. Takiben, otolog HTG grefti kullanılan hastalarda pes anserinus üzerinden $5 \mathrm{~cm}$. oblik insizyon ile girilerek semitendinosus ve gracilis tendonları alınarak 4 kat olacak şekilde greft olarak hazırlandı. İlk önce tibial tünelin yeri belirlenerek tibial ÖÇB kılavuzu $55^{\circ}$ açı ile ÖÇB' ın tibial yapışma yerine yerleştirildi. Takiben kılavuz teli yerleştirildi. Kılavuz teli yerinde bırakılarak, UDA için tibia hazırlandı. Tibial komponent için kesiler yapılırken kılavuz teline çok yakın olmamasına dikkat edildi. Daha sonra tibial tünel greft çapına uygun olarak hazırlandı. Tibial tünel hazırlandıktan sonra femoral tünel kılavuzu saat 10 ya da 2 pozisyonunda posterolateral duvarın 1.5 $\mathrm{mm}$ önünde olacak şekilde yerleştirildi. Kılavuz teli yerleștirildi ve yerinde bırakılarak UDA için femur hazırlandı. Tibial ve femoral denemeler sonrası ilk önce femoral tünel hazırlandı ve sonrasında sabit platformlu (Zimmer® Unicompartmental Knee Replacement, USA) unikondiler çimentolu diz protezi yerleştirildi. UDA sonrasında greft yerleştirildi. Femoral tespitte tünel içi tespit (AperFix® ${ }^{\circledR}$ System, Cayenne Medical, Scottsdale, USA) kullanıldı. Tibial tünel tespitinde biodegradable vida kullanıldı. Hiçbir hastada notchplasti ihtiyacı olmadı. Ameliyat sonunda 1 adet $500 \mathrm{~mL}$ hacimli hemovak dren yerleştirilerek katlar anatomisine uygun olarak kapatıldı. Yara yeri pansumanı yapılarak elastik bandaj sarıldı ve takiben turnike açıldı.

Ön çapraz bağ ameliyatı yapılan bazı hastalarda hastanın tercihi ve aktivitesi -hafif ve ılımlı göz önüne alınarak allogreft kullanıldı.

\section{Ameliyat sonrası dönem:}

Ameliyat sonrası tüm hastaların AP ve lateral diz radyografileri elde edildi. Ağrı kontrolü tramadol $\mathrm{HCl}$ (Contramal, $100 \mathrm{mg} / 2 \mathrm{ml}$ ampul) iv infüzyon şeklinde 1000 cc serum fizyolojik $2 \times 1$ ile sağlandı. Toplam Tramadol HCl dozu 400 mg üzerine çıkılmadı. Ağrı kontrolü için ek olarak parasetamol verilmedi. Her iki grupta yer alan hastalara 20 dakika/saat olacak şekilde ilk 12 saat boyunca saat başı, sonrasında 2 saatte bir buz torbası ile soğuk uygulama 2 gün yapıldı. Erken pasif harekete ertesi gün fizyoterapist eşliğinde başlandı. Hastalarda yürüteç kullanıldığı ve ameliyat sonrası rehabilitasyon daha kontrollü ve yavaş yapıldığı için breys kullanımına gerek duyulmadı.

Çalışma amacı ile 24 saatte drenden gelen kanama miktarı kayıt altına alınarak 24 saatin sonunda drenler çıkartıldı.

\section{3. İstatiksel analiz:}

Çalışmanın istatiksel analizleri SPSS 22.0 paket programı kullanılarak yapıldı. Verileri tanımlarken tanımlayıcı istatistikten, gruplar arası farkın tespiti için 
bağımsız gruplarda non-parametrik t (Mann-Whitney $\mathrm{U}$ testi) testi kullanıldı. $\mathrm{p}<0,05$ değeri istatiksel olarak anlamlı kabul edildi. Sonuçlar ortanca (minimummaksimum) olarak verildi.

\section{Bulgular}

Grup A 28, Grup B ise 18 hastadan oluşmakta idi. Grup A'yı oluşturan hastaların 26'sı kadın 2'si erkek idi. Grup B, 17 kadın, 1 erkek hastadan oluşmakta idi. Gruplar; yaş, cinsiyet, kilo ve boy açısından karşılaştırılabilir idi. Hastaların demografik özellikleri tablo 1 de verilmiştir.
Hiçbir hastada transfüzyon intiyacı olmadı. Her iki grup arasında hemovak drenden ölçülen kanama miktarları arasında istatiksel bir fark saptanmadı $(p=0.86)$ (Tablo 1).

Grup B'de 10 hastada otolog HTG, 8 hastada allogreft kullanılmış idi. Hemovak drenden ölçülen kanama miktarı otolog HTG kullanılan grupta allogreft kullanılan hastalara göre daha fazla idi $(p=0.043)$ (Tablo 2).

Grup Aile otolog HTG ve allogreft kullanılan hastaların drenden ölçülen kanama miktarları karşılaştırıldığında istatiksel olarak bir fark saptanmadı $(p=0.058$ ve $p=$ 0.65).

Tablo 1 Grupların demografik özellikleri ve ameliyat sonrası dönem kanama miktarları

\begin{tabular}{|c|c|c|c|}
\hline & GRUP A (n=28) & GRUP B (n=18) & $\mathbf{p}$ \\
\hline CINSIYET & $26 \mathrm{~K} / 2 \mathrm{E}$ & $17 \mathrm{~K} / 1 \mathrm{E}$ & \\
\hline YAŞ (yıl) & $61.32(50-76)$ & $60.06(46-74)$ & 0.65 \\
\hline BOY (cm) & $159.1(150-185)$ & $162.0(155-175)$ & 0.08 \\
\hline VÜCUT AĞIRLIĞI (kg) & $78.93(60-105)$ & $80.28(65-110)$ & 0.96 \\
\hline TARAF (sağ / sol) & $12 / 16$ & $9 / 9$ & n.s \\
\hline DREN (mL) & $350.54(100-650)$ & $358.33(200-550)$ & 0.86 \\
\hline
\end{tabular}

Tablo 2

Grup B'de allogreft ve hamstring tendon grefti kullanılan hastaların demografik özellikleri ve ameliyat sonrası dönem kanama miktarları

\begin{tabular}{|c|c|c|c|}
\hline & $\begin{array}{c}\text { HTG } \\
(\mathrm{n}: 10) \\
\text { Ortanca(min-maks.) }\end{array}$ & $\begin{array}{c}\begin{array}{c}\text { Allogreft } \\
(\mathrm{n}: 8)\end{array} \\
\text { Ortanca(min-maks.) }\end{array}$ & p \\
\hline CINSIYET (k/e) & $9 / 1$ & $8 / 0$ & 0,8 \\
\hline YAŞ (yıl) & $58,7 \quad(46-74)$ & $61,2(51-71)$ & 0,6 \\
\hline BOY $(\mathrm{cm})$ & 161,1 & $162,5(160-165)$ & 0,3 \\
\hline VÜCUT AĞIRLIĞI (kg) & $76(65-110)$ & $85(70-100)$ & 0,07 \\
\hline TARAF (sağ/sol) & $6 / 4$ & $3 / 5$ & 0,5 \\
\hline DREN (mL) & $417,5(200-550)$ & $315,6(225-425)$ & $0,043^{*}$ \\
\hline
\end{tabular}




\section{Tartışma}

Yapmış olduğumuz çalışmanın sonuçları değerlendirildiğinde, unikondiler diz artroplastisi ile kombine ön çapraz bağ rekonstrüksiyonunun, tek başına yapılan unikondiler diz artroplastisine göre ameliyat sonrası dönemde kanamayı belirgin olarak arttırmadığı görülmüştür. Ek olarak, beklendiği şekilde allogreft kullanılan hastalarda kanama miktarı otolog hamstring tendon grefti kullanılan hastalara göre daha azdır.

Ameliyat sonrası dönemde gelişen hemartroz, eklem kıkırdağı hasarı, sinovit ve ağıı, eklem içi fibrozis ve beraberinde hareket kısıtlıığına yol açar (20). Bu sebeple eklem içi dren kullanımı ve diğer hematom gelişimini engellemeye yönelik yöntemlerbuz uygulama, traneksamik asit vb. kullanılmaktadır $(20,21)$.

Unikondiler diz artroplastisinde, daha az yumuşak doku ve kemik kesisi ile medüller kanalın açılmaması teorik olarak TDA göre daha az kanamaya neden olur (22,23). Ancak, bu kanama olmayacağı anlamına gelmez ve ameliyat öncesi yapılan değerlendirmelerde, hasta yaşı, komorbiditeler ve dini inançlar sebebi ile kanama ve transfüzyon intiyacının olabileceği hasta ile paylaşıımalıdır (4).

UDA ameliyatlarında ileri yaş, ameliyat öncesi düşük hemoglobin seviyesi, düşük molekül ağırlıklı heparin kullanımı ve cerrahi sürenin uzaması kanama ve dolayısıyla transfüzyon intiyacını arttırmaktadır $(22,24)$. Ameliyat esnasında i.v. ya da lokal traneksamik asit ve kemik mumu kullanımı ile ameliyat sonrası kanama \%50 oranında azaltılabilinir (3). Ek olarak minimal invaziv cerrahi teknik de ameliyat sonrası kanamayı belirgin olarak azaltmaktadır (25). UDA sonrası kanama miktarı traneksamik asit ve kemik mumu kullanımı ile yaklaşık $250 \mathrm{~mL}$ olarak bildirilmiştir (3). Başka çalışmalarda da hemoglobin değerlerinde ortalama $1 \mathrm{~g} / \mathrm{dL}$ ile $2.73 \mathrm{~g} / \mathrm{dL}$ kadar düşme olduğu belirtilmektedir $(4,25)$. Bu değerler, yaklaşık olarak 1-2 ünite kan kaybını göstermekte olup, miktar olarak mevcut çalışmanın sonuçları ile paralellik göstermektedir.
Artroskopik ön çapraz bağ ameliyatları sonrasında görülen kanama miktarı rekonstrüksiyon yöntemi, notchplasti ve kullanılan greft - oto, allo ile ilișkilidir (26). Kanamanın ana kaynağı ise kansellöz kemiktir (20). Turnike kullanımının ameliyat sonrası dönemde kanama üzerine bir etkisi yoktur (27). Notchplasti yapıldığında ise ameliyat sonrası kanama belirgin olarak artmaktadır $(20,28)$. Çalışmamızda notchplasti hiçbir hastada yapılmadığından bu konuda bir yorum yapmamız mümkün değil. Ancak, bu çalışmalarda cerrahi tekniklerve kullanılan greftler-BPTB açısından fark olmamasına rağmen sonuçlar çok farklıdır. Bu da başka kișisel faktörlerin de kanama üzerine etkisinin olabileceğini düşündürmektedir. Otolog HTG ile ÖÇB rekonstrüksiyonu yapılan bir çalışmada ise kanama ortalama $60.3 \mathrm{~mL}$ olarak belirtilmektedir (12).

Çalışmanın geriye dönük dizaynı ve hasta sayısının azıı̆ı zayıf yanlarını oluşturmaktadır. Daha çok vaka sayısının yer aldığı, daha çok parametrenin değerlendirildiği, ileri dönük çalışmaların yapılması gerektiğini düşünmekteyiz.

\section{Sonuç}

Mevcut çalışmaların ışığında değerlendirildiğinde ise ÖÇB ile kombine yapılan UDA de, ön çapraz bağ rekonstrüksiyonun oluşturduğu kanama miktarı özellikle allogreft kullanıldığında inmal edilebilir seviyelere inebilmektedir. Ancak, yaklaşık 500 $\mathrm{mL}$ kadar bir kanama da olabileceği göz önünde bulundurulmalıdır. Dolayısıyla cerrahiden bağımsız kişiye ait faktörler de göz önüne alındığında ameliyat sonrası dönemde hematom oluşumuna bağlı komplikasyonların önlenebilmesi için dren kullanımını önermekteyiz.

\section{Kaynaklar}

1. Asanuma K, Ito H, OgawaA, Asanuma Y, Yoshikawa T, Hasegawa M, Sudo A. Recurrent hemarthrosis after unicompartmental knee arthroplasty. Orthopedics. 2011;34(9):578-80.

2. Berend KR, Morris MJ, Lombardi AV. Unicompartmental knee arthroplasty: incidence of transfusion and symptomatic thromboembolic disease. Orthopedics.2011;33(9Suppl):8-10. 
3. Zhang Q, Zhang Q, Guo W, Liu Z, Cheng L, Zhu G. No need for use of drainage after minimally invasive unicompartmental knee arthroplasty: a prospective randomized, controlled trial. Arch Orthop Trauma Surg. 2015;135(5):709-13.

4. Schwab PE, Lavand'homme P, Yombi JC, Thienpont E. Lower blood loss after unicompartmental than total knee arthroplasty. Knee Surg Sports Traumatol Arthrosc. 2015;23(12):3494-500.

5. Tinius M, Hepp P, Becker R. Combined unicompartmental knee arthroplasty and anterior cruciate ligament reconstruction. Knee Surg Sports Traumatol Arthrosc. 2012;20(1):81-7.

6. Clayton RA, Court-Brown CM. The epidemiology of musculoskeletal tendinous and ligamentous injuries. Injury. 2008;39(12):1338-44.

7. Ventura A, Legnani C, Terzaghi C, lori S, Borgo E. Medial unicondylar knee arthroplasty combined to anterior cruciate ligament reconstruction. Knee Surg Sports Traumatol Arthrosc. 2017;25(3):675-80.

8. White SH, Ludkowski PF, Goodfellow JW. Anteromedial osteoarthritis of the knee. J Bone Joint Surg Br. 1991;73: 582-6.

9. Deschamps G, Lapeyre B,. Rupture of the anterior cruciate ligament: a frequency unrecognized cause of failure of unicompartmental knee prostheses. Apropos of a series of 79 Lotus prostheses with a follow-up of more than 5 years. Rev Chir Orthop Reparactice Appar Mot. 1987;73:544-51.

10.Boissonneault A, Pandit H, Pegg E, Jenkins C, Gill $\mathrm{SH}$, Dodd CAF, et al. No difference in survivorship after unicompartmental knee arthroplasty with or without an intact anterior cruciate ligament. Knee Surg Sports Traumatol Arthrosc. 2013;21:2480-6.

11. Mancuso F, Hamilton TW, Kumar V, Murray DW, Pandit $\mathrm{H}$. Clinical outcome after UKA and HTO in ACL deficiency: a systematic review. Knee Surg Sports Traumatol Arthrosc. 2016;24:112-22.

12.Bahl V, Goyal A, Jain V, Joshi D, Chaudhary D. Effect of hemarthrosis on the rehabilitation of anterior cruciate ligament reconstruction- single bundle versus double bundle. J Orthop Surg Res. 2013; 19;8:5.

13. Reilly TJ, Gradisar IJ, Pakan W, Reilly M. The use of postoperative suction drainage in total knee arthroplasty. Clin Orthop Relat Res. 1986;208:238-42. 14. Li C, Nijat A, Askar M. No clear advantage to use of wound drains after unilateral total knee arthroplasty: a prospective randomized controlled trial. J Arthroplasty. 2011;26(4):519-22.

15. Ares O, Seijas R, Hernandez A, Castellet E, Sallent A. Knee arthroplasty and bleeding: when to remove drainages. Knee Surg Sports Traumatol Arthrosc. 2013;21:393-7.

16.Zhang QD, Guo WS, Zhang Q, Liu ZH, Cheng LM, Li ZR. Comparison between closed suction drainage and nondrainage in total knee arthroplasty: a metaanalysis. J Arthroplasty. 2011; 26(8):1265-72.

17.Jenny JY, Boeri C, Lafare S. No drainage does not increase complication risk after total knee prosthesis implantation: a prospective, comparative, randomized study. Knee Surg Sports Traumatol Arthrosc . 2001;9(5):299-301.

18. Kim YH, Cho SH, Kim RS. Drainage versus nondrainage in simultaneous bilateral total knee arthroplasties. Clin Orthop Relat Res. 1998; 347:18893.

19. Fan $Y$, Liu $Y$, Lin J, Chang $X$, Wang W, Weng $X S$. Drainage does not promote post-operative rehabilitation after bilateral total knee arthroplasties compared with nondrainage. Chin Med Sci J. 2013;28(4):206-10.

20.Camillieri G, Margheritimi F, Maresca G, Mariani PP. Postoperative bleeding following notchplasty in anterior cruciate ligament reconstruction: thermal radio frequency versus powered instrumentation. Knee Surg Sports Traumatol Arthrosc. 2001;9:12-14. 21. Ruffilli A, Buda R, Castagnini $F$, Di Nicolantonio $D$, Evangelisti G, Giannini $S$ et al. Temperaturecontrolled continuous cold flow device versus traditional icing regimen following anterior cruciate ligament reconstruction: a prospective randomized comparative trial. Arc Orthop Trauma Surg. 2015; 135: 1405-10.

22.Lombardi AV Jr., Berend KR, Walter CA, AzizJocobo J, Cheney NA. Is recovery faster for mobilebearing unicompartmental than total knee arthroplasty. Clin Orthop Relat Res. 2009;467:1450-7.

23. Yang KY, Wang MC, Yeo SJ, Lo NN. Minimally invasive unicondylar versus total condylar knee arthroplasty- early results of a matched- pair comparison. Singap Med J. 2003; 44: 559-62.

24.Bong MR, Patel V, Chang E, Issack PS, Hebert R, Di Cesare PE. Risks associated with blood transfusion after total knee arthroplasty. J Arthroplasty.2004; 
19:281-7.

25.Jeer PJS, Cossey AJ, Keene GCR. Haemoglobin levels following unicompartmental knee arthroplasty: Influence of transfusion practice and surgical approach. The Knee. 2005;12:358-61.

26. Karaaslan F, Karaoğlu S, Yurdakul E. Reducing intra-articular hemarthrosis after arthroscopic anterior cruciate ligament reconstruction by the administration of intravenous tranexamic acid. Am J Sports Med. 2015;43(11):2720-6.

27.Wu H, Chen LX, Li YL, Wu Q,Wu QL, Ning GZ et al. Tourniquet used in anterior cruciate ligament reconstruction: a system review. Eur J OrthopSurg Traumatol. 2014;24:999-1003.

28. Pape D, Seil R, Adam F, Gödde S, Georg T, Rupp S, et al. Blood loss in anterior cruciate ligament (ACL) reconstruction with and without intercondylar notchplasty: does it affect the clinical outcome? Arch Orthop Trauma Surg. 2001;121:574-7. 